\title{
Ergonomic Improvements for Foundries
}

\author{
-----Final Report-----
}

\author{
$6 / 18 / 2002$
}

\author{
Frank Peters \\ 515/294-3855 \\ fpeters@iastate.edu
}

Patrick Patterson

515/294-8661

ppatters@iastate.edu

Industrial and Manufacturing Systems Engineering Department Iowa State University 2019 Black Engineering Bldg.

Ames, IA 50011-2164

515/294-3524 - FAX

This project was funded by the U.S. Department of Energy (DOE) award No. DE-FC00700ID13849. However, any opinion, findings, conclusion, or recommendations expressed herein are those of the authors and do not necessarily reflect the views of the DOE 


\section{INTRODUCTION}

The goal of this project was to make improvements to the production systems of the steel casting industry through ergonomic improvements. Because of the wide variety of products, the wide range of product sizes, and the relatively small quantities of any particular product, manual operations remain a vital part of the production systems of the steel casting companies. Ergonomic improvements will assist the operators to more efficiently and consistently produce quality products.

Any ergonomic problems are critical to the production process. It is widely accepted that there is a strong correlation between ergonomic problems with a job and the turnover of staff experienced for that job. Any improvements in the workplace will result in less turnover. During our project review meetings, many companies have noted that not only productivity but also product quality suffers while they are training new employees. This reduction in quality is fixed via rework, which unnecessarily consumes more energy. The proposal assumed a reduction of rework by $1-2 \%$ and a scrap reduction of $0.05 \%$. The research team feels that these values are on target.

One of the first tasks undertaken for the project was a survey on ergonomic problems mailed to all U.S. steel foundries. The results will be reviewed here.

Four 1-day workshops were offered in June and July of 2000, which attracted over 40 participants. During these events, the ergonomic risk factors were discussed, and a methodology to evaluate jobs was presented. The risk factors will be briefly reviewed here.

Student researchers conducted ergonomic assessments at twenty-six companies. During these 12 day visits, five jobs, chosen by the company, were studied. Videotape of the jobs was obtained, the dimensions of the workstation were taken, and the operators and supervisors were interviewed.

Many of these problems have existed for an extended period of time, during which different solutions have been attempted and failed. The research team took a more holistic look at the job, to develop a solution that will be beneficial to the worker, and is also practical. To this end, two 'ergonomic solution work sessions' were held in 2001. During these events, short videotape segments were reviewed and the ergonomic hazards identified. After this, the research team presented a proposed solution and the justification. The interactive nature of the events allowed the team to collect additional industrial input to improve the solutions.

\section{THE BASIC ERGONOMIC RISK FACTORS}

There is evidence that WRMD result from repeated stress caused by ergonomic hazards, or risk factors (USDOL, 1990). Ergonomic risk factors are defined as job attributes or exposures that increase the probability of the occurrence of musculoskeletal disorders. Silverstein et al. (1986, 1987) demonstrated a relationship between occupational exposures in high force-high repetition tasks and injury pathology. Research reports on the risk factors associated with these injuries 
(Armstrong, 1986; Erdil et al, 1994; Hoozemans et al., 1998; Leamon, 1994; Marras et al., 1995; Vikari-Juntura, 1997) agree that some WRMD are associated with sudden overload in manual handling activities, heavy physical work involving manual handling tasks, repetitive push/pull, forceful motions, working in awkward positions, vibration, and lifting/carrying excessive weights. Garg and Moore, (1992), as well as Pope (1989) indicated that heavy physical work, repeated lifting and twisting are consistently associated with greater injury risk.

The basic ergonomic risk factors involve concerns related to worker characteristics, task characteristics, and environmental characteristics, derived from the results of the studies mentioned above and others.

1. Force (its inappropriate use or application): Excessive force contributes to muscle fatigue, impedes adequate blood flow, and induces microtrauma, particularly in situations having static work or intermittent work with high intensity demands.

2. Posture (inappropriate positioning or fit): Holding or using the body and/or extremities in extreme postures contributes to inflammation. This is especially true if the position is maintained for a long time.

3. Duration (how long an action takes place): A prolonged series of repeated, short cycle contractions or low/moderate level contractions sustained for long periods of time can cause local muscle fatigue by impeding blood flow, restricting normal removal of waste products, and reducing nutrient supplies to the muscle.

4. Power (rate of doing work): Power triggers many of the body's responses to work; excessive power demand in a task can cause both local and general fatigue.

5. Repetition (too much of a bad thing): Repetitive use of muscles (especially small muscle groups) and movement around the joints can result in metabolic and circulatory changes that decrease the flow of nutrients to involved muscle groups.

6. Environmental Factors (temperature, humidity, etc.): Extreme temperatures, particularly when coupled with high humidity, can affect performance. Low temperatures in limbs can result in constriction of the blood vessels causing a loss of tactile sensitivity, and decreased grasp and dexterity.

7. Behavior (information, errors, etc.): The human is the most variable component in your system; errors, mistakes, etc., are commonplace in a poorly designed system.

8. Vibration (tool or equipment motion): Use of vibrating tools can cause spasm of the small blood vessels of the hand, wrist, and arm. The decreased circulation can have a direct effect on the muscles of the upper extremity resulting in numbness and tingling, episodic blanching, and pain in the fingers. Performance effects are reduced grip strength and finger dexterity. 
9. Acceleration and Velocity (pace, smoothness of action, etc.): Velocity and acceleration of actions ("jerkiness" of movement) are predictive of upper extremity WRMD. This factor may be equally applicable to other body parts, such as the back.

10. Contact Trauma (a body part presses against an external object): Contact stress results in a sustained force which may result in too much mechanical stress on the tissues; it may also shut off blood flow to an area, causing fatigue to occur more quickly; impact shocks of an object against the body may also result in tissue trauma.

11. Combinations (more than one risk factor present in an activity): The presence of more than one risk factor is thought to increase the risk of developing WRMD; for example, the quick, repetitive, forceful motions required when using a grinder.

Other factors may be important in a given set of circumstances, such as:

- Age (physical changes occur as a person ages constraining job design)

- Gender (physical differences must be accounted for when designing a task)

Understanding these basic risk factors allows for the development of industry specific checklists, as well as job specific analysis tools, for diagnosing and correcting potentially injurious jobs.

\section{INDUSTRY SURVEY ON ERGONOMICS}

One of the first tasks was to conduct a survey of industrial personnel on their views, experience, and successes in the area of ergonomics. The purpose of the survey was to assess the status in the industry, and to assist the research team in developing material for the workshops held during the summer of 2000. This survey was mailed to all steel foundries in the U.S., and 35 responses were received. Besides some administrative questions, the survey contained 4 multi-part questions. The actual questions asked are underlined below. A summary of the responses is provided following each question.

1) Please evaluate the following issues in terms of the seriousness of the physical problems, and the relative occurrence of the events, for your company. Put a check in the appropriate boxes. Add any additional physical concerns that are an issue for your company.

The following table shows the number of responses for each of the cells of the matrix. For instance, ten companies indicated that shoulder problems were 'not an issue.'

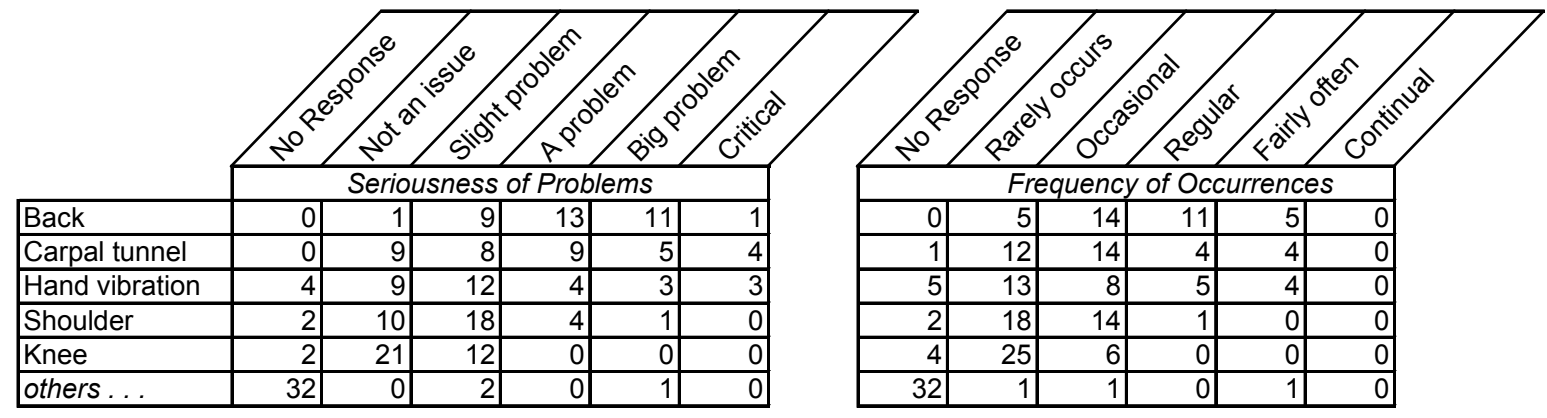


To compare the magnitude of the problem, the responses from the 'seriousness' and 'frequency' matrices were combined. To accomplish this, the responses were assigned a numerical value, as shown in the table below. For each body part, the respondents' 'seriousness' response was multiplied by the corresponding 'frequency' response. The average of these products is shown on the right, in the shaded column. As can be seen, the survey indicates that back problems are the biggest issue.

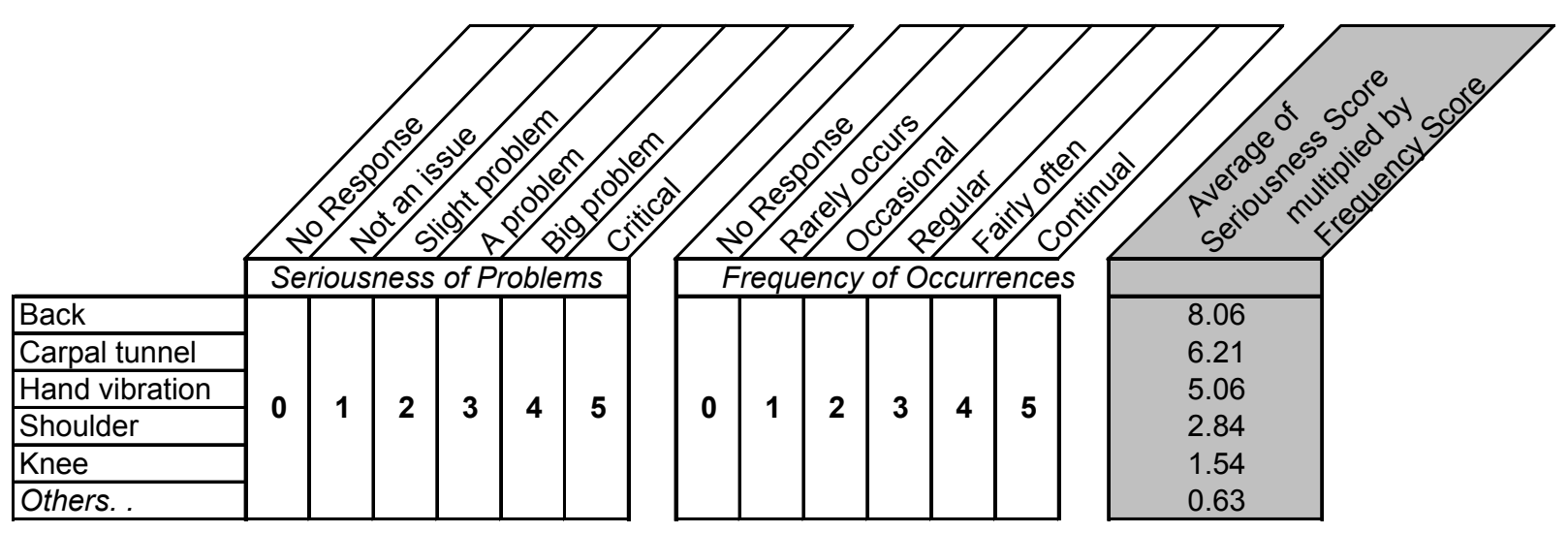

2) Similar to the previous question, rate the following jobs and tasks on their role in contributing to ergonomic problems.

The following table shows the number of responses for each of the cells of the matrix.

\begin{tabular}{|l|r|r|r|r|r|r|r|r|r|r|r|r|}
\hline Hand grinders & 3 & 4 & 12 & 8 & 6 & 2 \\
\hline Mold making & 3 & 5 & 10 & 10 & 7 & 0 \\
\hline General labor & 5 & 7 & 13 & 7 & 3 & 0 \\
\hline Stand grinders & 10 & 10 & 11 & 3 & 1 & 0 \\
\hline Shakeout & 4 & 13 & 11 & 6 & 1 & 0 \\
\hline Swing grinders & 10 & 10 & 11 & 3 & 0 & 1 \\
\hline Welding & 5 & 13 & 13 & 3 & 1 & 0 \\
\hline Core making & 5 & 16 & 10 & 2 & 2 & 0 \\
\hline Inspection & 3 & 18 & 13 & 1 & 0 & 0 \\
\hline Arc air \& burn & 6 & 15 & 11 & 2 & 1 & 0 \\
\hline Heat treatment & 7 & 22 & 6 & 0 & 0 & 0 \\
\hline Others. . & 32 & 0 & 1 & 2 & 0 & 0 \\
\hline
\end{tabular}

Similar to question 1, each of the responses was assigned a numerical value. The product of the 'seriousness' and 'frequency' responses was calculated, and the average is shown in the shaded column below. The survey indicates that hand grinding is the job with the most issues. 


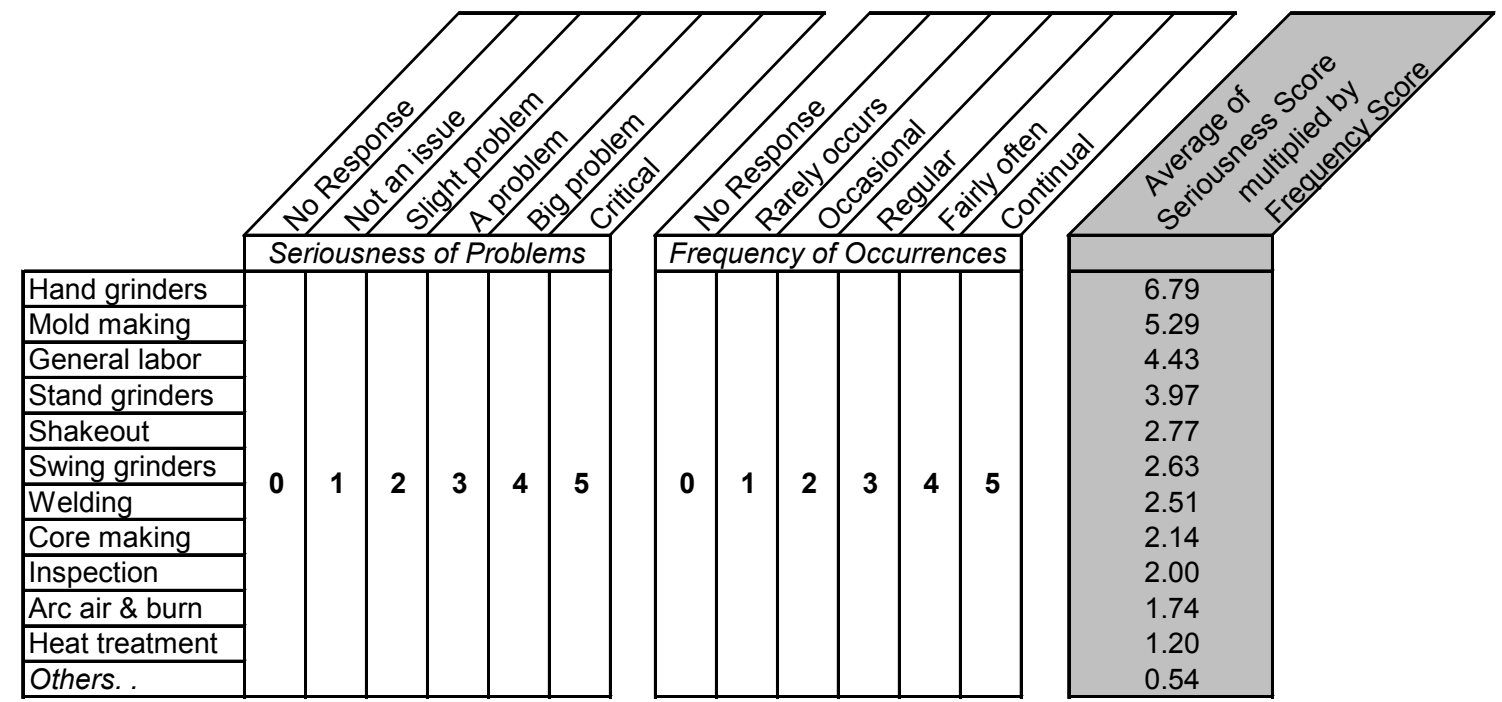

3) Which three ergonomic problems have resulted in the largest losses for your company?

Authors' Notes:

The responses were grouped in categories, which are in bold.

Multiple responses are indicated with a number following the response

\section{Upper Extremity:}

Carpal tunnel -13

Hand vibration -2

Tendonitis \& epizondylitis in elbows -2

Hand injuries

Hand and arm vibration from pencil grinders

Tendonitis in wrists

\section{Lower Extremity:}

Foot injuries -2

Knee injuries

Knee injuries from tripping

Torso:

Strains (back) -22

Hernia

Arm, shoulder, and back from lifting at snag grinding

\section{Other Injuries:}

Strains (other) -10

Eye injuries -3

\section{Related to Specific Jobs:}

Hand grinders -3

Other:

Green sand hand mold lifting

Employees with poor health/lifestyle

Overtime

Not using lifting equipment, asking for assistance, or following procedures 
4) What has been your company's best ergonomic solution(s)?

Authors' Notes:

The responses were grouped in categories, which are in bold.

Multiple responses are indicated with a number following the response

Improved education and training of employees:

Training-3

Instruction in proper lifting \& pushing-3

Job observation training

Talks from chiropractor that specializes in industrial injuries.

Using our comp insurance co. to instruct, insight, and improve our attitudes \& work environment

Change of Equipment:

Robotics -2

Equipment redesign

Tool redesign

Use of pneumatic drivers instead of hand wrenches

Change in Work Station/Area:

Scissors lift tables -2

Adjusting machine/platform heights

Chair redesign

Use of manipulators

Workstation redesign

Put pencil grinder in holder and bring part to grinder

Material Handling Improvements:

Material handling

Mechanical pour assist

Purchasing equipment to automate/reduce lifting of material

Station cranes

Use of tongs in knockoff area

Installation of JB Hoists to load and unload worktables

Better Safety Equipment

Back supports, fitted supports, and lifting belts $-6^{* *}$

Better safety equipment-3

Anti-vibration gloves and tools

Changed boot requirements

Fatigue mats

Job Rotation: ***

Job rotation -4

Moving employees early when a muscular skeletal problem occurs 


\title{
Other Improvements:
}

Buy supplies in smaller quantities (less to lift)

Micro-stretching

Monitoring

Reduce weight limit on lifting

Being involved in treatment of injury

Job safety analysis

Restructure safety committees \& procedures.

Hire smarter people

Make lighter castings

Replace snag grinding with arc wash

\section{Other Responses:}

Not Applicable

No good solutions found that are acceptable to employees and management

\begin{abstract}
Authors' Footnotes:
** Although several companies are reporting that they are successfully using back supports, there is evidence that they actually contribute to the problem by transferring the stress to the next most vulnerable area and by providing a false sense of security.

*** Job rotation does not eliminate the problem, but causes more employees to be exposed to the hazard. It may be an acceptable practice if the hazard is minimized to the extent feasible.
\end{abstract}

\section{ERGONOMIC ASSESSMENT VISITS AND EVALUATIONS}

The major portion of our efforts was visits to participating companies to conduct ergonomic assessments. Invitations were extended to all members of the Steel Founders' Society of America, and the research team visited twenty-six steel foundries. Each assessment participant was asked to identify five jobs that they wanted to be evaluated. The ergonomic assessment lasted from one to two days.

The ergonomic assessments consisted of several tasks in an effort to fully reveal the issues surrounding the potential ergonomic problems. The researchers interviewed the operators about the job, any physical complaints they had, and their suggestions. Similarly, the supervisors were also queried to gain their perspective. The targeted jobs were videotaped to allow further analysis. Workstation specifics, such as the position of equipment, height of tables, and the forces required to produce movements were recorded. The worker injury history was also obtained for the jobs that were evaluated.

Via the videotapes and other supporting information, thorough assessments of all of the jobs were conducted by the research team. The team was made up of two senior researchers (one with expertise in ergonomics and the other in metalcasting production), the student researchers who conducted the majority of the visits and were most familiar with the particular jobs, and researchers with design engineering skills to provide an outside perspective.

The purpose of the review sessions was to develop recommendations for the individual companies and to develop solutions that would work for the industry, or at least a subset of the industry. The jobs that were assessed during the industrial visits were grouped into seven 
categories. This allowed the research team to make comparisons and contrasts among the jobs at different companies, which was very beneficial.

The companies selected the jobs to be analyzed on the basis of being potentially problematic, or definitely problematic, from an ergonomic standpoint. A total of 113 jobs were evaluated, and the breakdown of these jobs into different categories is provided in Table 1.

\section{Table 1: Number of jobs studied for each of the job categories.}

$\quad$ Job Category
Green Sand Molding
No Bake Mold \& Core Making
Coresetting
Ladle \& Furnace Prep.
Pouring
Shakeout
Blast Clean
Burn off
Hand Grind
Stand Grind
Swing Grind
Welding \& Arc Air
Miscellaneous

Total

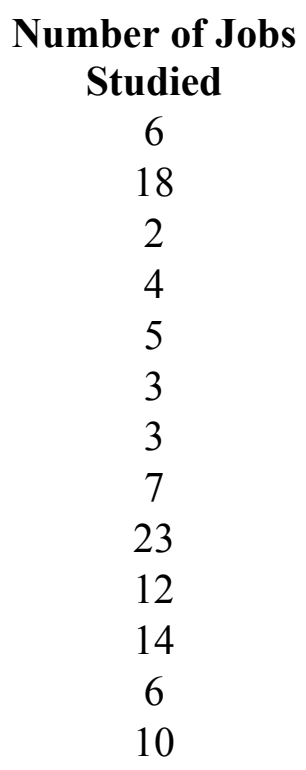

113

The operations and process flow at the majority of the steel foundries in the U.S. have many commonalities. However, the specific procedures and designs of the workstations are unique. Proposed solutions have been provided to each of the companies who participated in the project. Providing specific information about improving a particular workstation at a particular company would have limited benefit for other companies. Therefore, in this report, general findings that can be useful for companies that are analyzing their work practices are presented. We found many jobs that can be solved relatively easily. We also analyzed jobs for which a good ergonomic solution will be difficult to develop. This information can be used to develop longrange strategies for these operations. Several specific examples are presented to help illustrate our findings.

The jobs evaluated by the research team have been ranked according to the difficulty in making ergonomic improvements. This analysis shows that although there are some jobs that are difficult to improve from an ergonomic standpoint, there are others in which significant improvements can be made with little difficulty. The results are shown in Figure 1. We recognize that our ranking of the jobs into the various categories is subjective. We did receive feedback from some of the companies to justify our subjective decisions. 


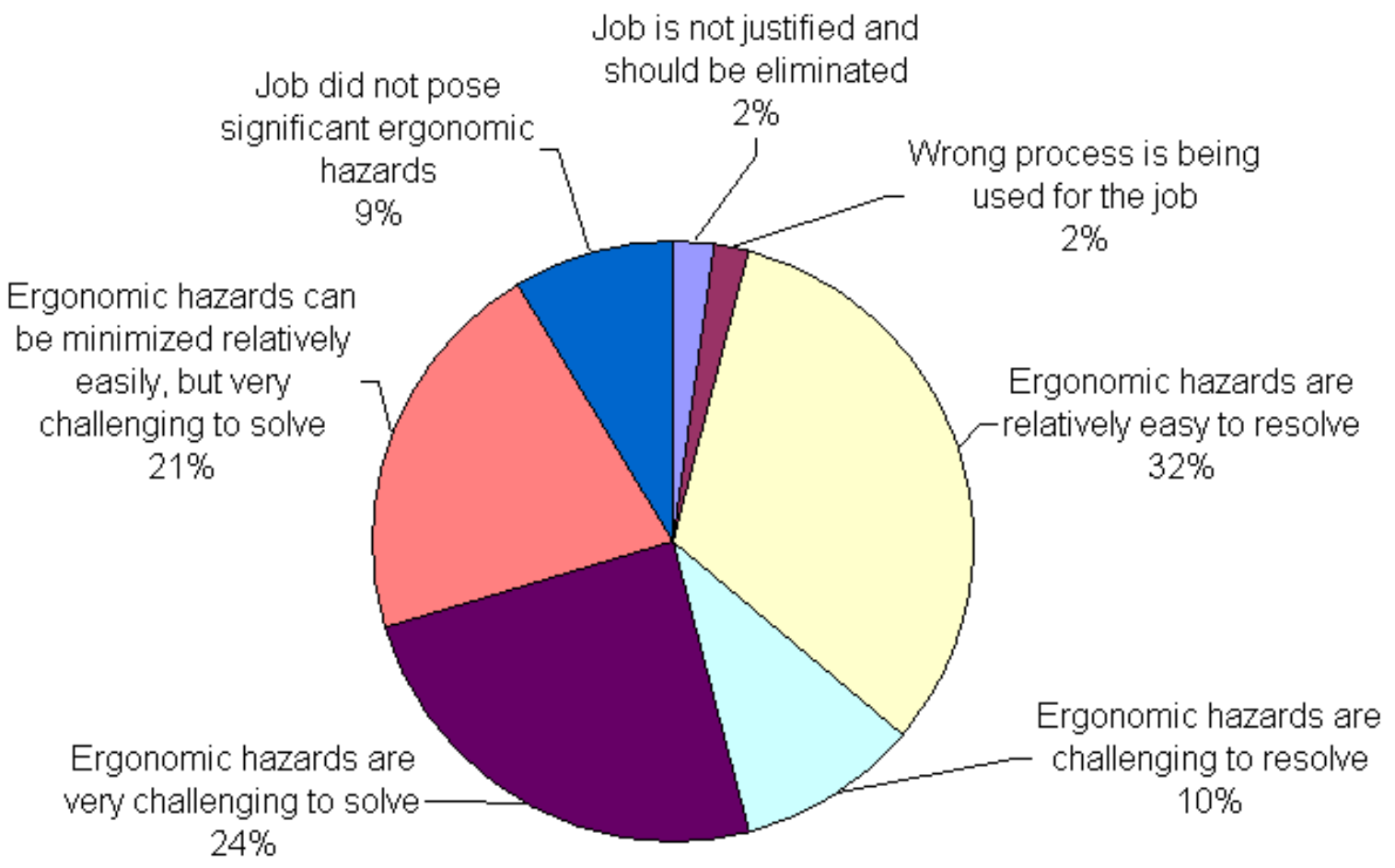

Figure 1: Percentage of jobs according to the difficulty in making ergonomic improvements to the processing portion of the job.

The jobs that tend to be easier to solve were spread among most of the companies we visited. Companies were, and are, encouraged to start seeking these types of jobs, and begin to make some substantial ergonomic improvements.

There were two jobs in which the research team did not feel that the activity was justified. Elimination of the job would obviously eliminate the ergonomic hazard, and improve productivity. There were 2 additional jobs in which we felt another process would be more appropriate, and much better from an ergonomic standpoint. Examples of these will be provided later. Nine percent of the jobs we examined were deemed to be very good from an ergonomic standpoint, and only minor recommendations were suggested.

We asked each company to identify five jobs. If the same job was studied at multiple companies, each instance was included in Figure 1. We constructed the graph in this manner, because it provides a breakdown of the difficulty to solve jobs in which companies identified. However, the results are skewed by the fact that hand grinding represents 23 of the 113 jobs, and nearly all of the jobs in the category labeled "Ergonomic hazards very challenging to solve."

Before analyzing any job, we often found it to be beneficial to break the job into two parts: the material handling of the product and the actual process being performed. Figure 2 ranks the jobs according to the difficulty in solving the material handling portion the job. Note that for 30 jobs, the primary operation was handling of the product (i.e. loading heat treat racks, coresetting, separating castings at shakeout), and these jobs are excluded from Figure 2, and only included in Figure 1. As shown in Figure 2, 21\% of the jobs did not involve any material handling. Most of 
these cases were a result of processing very large castings in which the operator could not handle. For the remainder of the jobs, the operator was involved in moving the product involved (i.e. castings, cores, refractory material.)

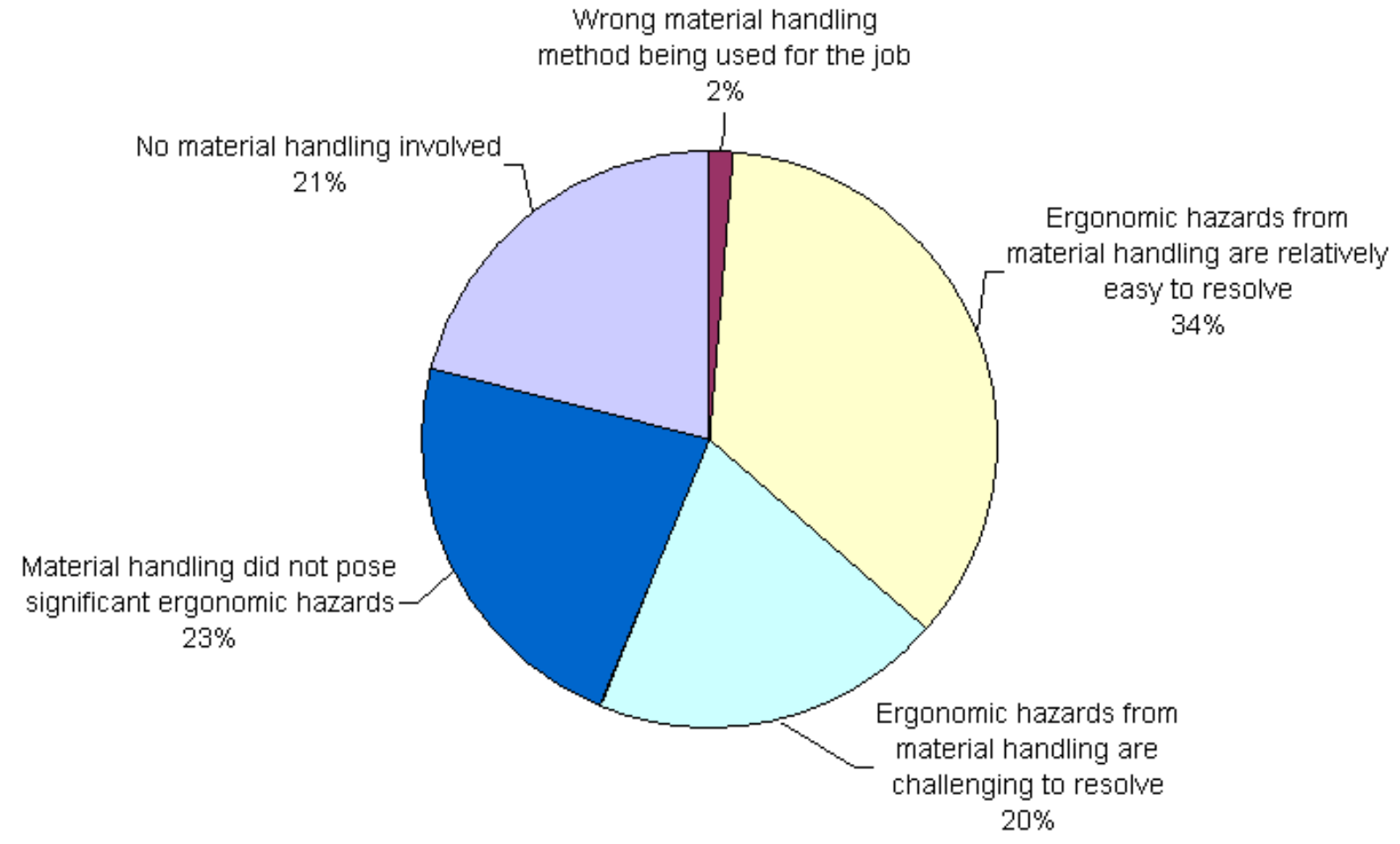

Figure 2: Percentage of jobs according to the difficulty in solving the material handling portion of the job.

Most of the jobs were selected by the company for us to analyze based on the ergonomic problems associated with the job. It is interesting to note that we found some jobs in which the ergonomic problems caused by the material handling portion to be more of a problem than those associated with the actual processing portion. This is significant, because the material handling issues are typically easier to solve.

As part of previous research work, Peters et al. reported that material handling in the steel casting industry is sometimes excessive and costly. He recommended to find ways to minimize or eliminate this expense. Elimination of manual material handling will also eliminate the associated ergonomic risks associated [Peters 1999 and Peters 2000].

\section{EXAMPLES OF PROBLEMS AND SOLUTIONS}

The purpose of the previous section was to present an overview of the jobs that were evaluated at a large variety of steel foundries. This section will provide specific examples to the different classifications of jobs shown in Figures 1 and 2. Because of the similarity of operations within the steel casting industry, some of these example solutions may be beneficial for your operation. However, no paper can provide a company with all of the solutions it needs to solve all the 
ergonomic problems associated with their operation. These examples are presented to demonstrate that many ergonomic problems are relatively easy to solve. These types of jobs should be identified in your company in order to quickly eliminate the ergonomic risk factors. These examples will also illustrate that some jobs are very problematic, and longer term solutions should be investigated.

\section{Job is not justified and should be eliminated}

One company who used gaggers in their large green sand molds was found to salvage the rebar after shakeout for reuse. Two to three workers were used during retrieval of the rebars, and were observed reaching and twisting over a large table. Another worker would then straighten the rebars for use in future molds. There were numerous ergonomic problems with these jobs. The team showed that the gaggers could be remelted and new rebar purchased, for less than the cost of the labor to separate the used gaggers. This suggestion not only eliminates the risk of worker injury, but also saves the company money.

Another very common example of this category of job is any unnecessary grinding that occurs on castings. Often this is done because the customer requirements are not clearly communicated to production personnel. This is a very common problem with some companies. Any reduction of the amount of production personnel time used for these activities will result in a direct reduction of the ergonomic problems, and an increase of productivity. Note that the excess processing of castings was not considered in the job breakdown presented in Figure 1.

\section{Wrong process is being used for the job}

Some companies were observed grinding castings that were too large for a stand grind operation (in excess of 50 pounds). Workers were trying to hold and maneuver these castings for long periods of time. These workers were in a high risk for shoulder, extremity and lower back injuries. Other methods of grinding such as hand or swing grinding would be a better way of removing material from these large castings.

Corewash is another job that has a number of different methods that can be employed. Some companies use brushes to apply the wash to the molds. The problem with this method is that the operator is required to assume a variety of poor postures. For large castings, these poor postures are often held for a long period of time. A better option would be to use flow coating to apply the corewash. This would allow the operator to assume a more neutral stance, and provide a more consistent quality coating.

\section{Ergonomic hazards that are relatively easy to resolve}

Furnace preparation for pouring in some companies involved workers using sledgehammers to reset wedges on the electrodes. The operator swinging the sledgehammer, coupled with the weight of the hammer, creates an extra amount of strain on the body. Large amounts of strain could lead to shoulder and back injuries. This was also very time consuming. An easy solution is to use a hydraulic porta-power to reset the wedges. Using the porta-power, and placing brackets on the wedges to serve as designated push points, eliminates the risk of physical injury while resetting the wedges.

Another area that is relatively easy to resolve is the improper heights of the control handles on sand mixers. The handles for overhead mixers are often too high for the worker to comfortably 
and safely move the mixer while filling patterns. This problem is easily solved with the addition of telescoping handles installed onto the existing handles of the mixer shown in Figure 3. This allows the worker to adjust the handles to a comfortable and safe working height, and to accommodate taller molds when needed.

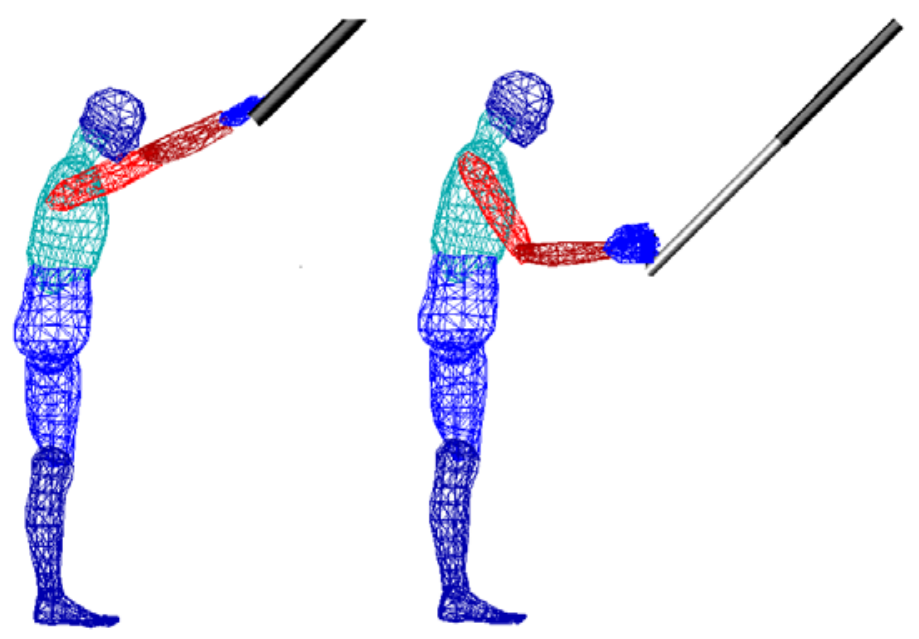

Figure 3: Current mixer handle position versus proposed mixer handle position.

\section{Ergonomic hazards that are challenging to resolve}

For companies with chemically bonded molding lines, many workers were found to be reaching while bending and twisting their back to screet off excess sand from filled flasks. Most of the time, the workers were using $3^{\prime}-4^{\prime}$ lengths of 2 x 4's as the screet. One of the suggestions the team made for this type of job was the installation of a powered screet as shown in Figure 4 . The incorporation of the powered screet will eliminate the need for the operator to apply force, and the chance for musculoskeletal injuries.

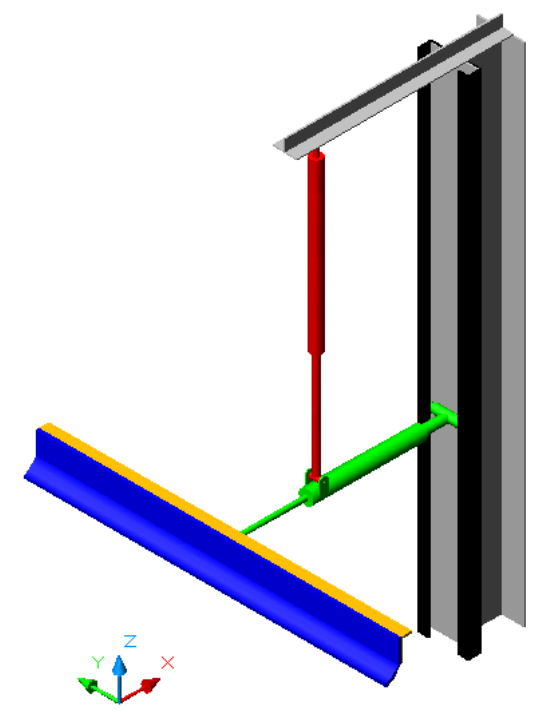

Figure 4: Hydraulically powered screet with hydraulic height adjustment. 


\section{Ergonomic hazards that are very challenging to resolve}

Hand grinding, which is found to be an ergonomic problem in most companies, is very challenging to solve. Because of its prevalence in the industry, a subsequent section of this paper will discuss this job in more detail.

Ladle cleaning is another very challenging hazard to solve in many companies. There will not be a good ergonomic solution to this job if the human is required to hold and manipulate the equipment used to break out the refractory materials. To solve the ergonomic problem, the operator interaction must be minimized or eliminated. To accomplish this, the chipper unit needs to be mounted on a machine, such as a skid steer tractor or a suspended boom that can be manipulated.

Serious consideration of how these jobs are performed is advised.

Ergonomic hazards that can be minimized relatively easily, but very challenging to resolve During swing grinding, the operator's torso is flexed forward much of the time to apply force on the grinding wheel. Further complicating the matter is the need for the operator to bend the upper torso to observe the grinding surface. The workstations studied had very little adjustability in the vertical direction. This resulted in the employees assuming many ergonomically poor body postures. Further complications arise from the variety of workpiece sizes and shapes. Within the same casting, the operator was forced to reach above the level of their shoulders and then stoop down to angles up to 90 degrees. In general, the torso should not bend more than 6 to 10 degrees from the vertical and the head should not tilt more than 15 degrees. When the torso is flexed forward, the lower back is supporting approximately $50 \%$ of the body's weight due to the weight of the head and upper body. This position can lead to damage in the back and neck even if no external load is being applied. Lower back pain was a frequent complaint of the swing grinders interviewed.

We propose using a handle that can be adjusted to compensate for the variation in grinding height. Two design concepts have been proposed to maintain safe postures while grinding parts of varying size. Of course, one of the requirements is that the handle is quickly adjustable.

The first design can be slide-fit over existing handles, as shown in Figure 5. The handles will operate at +90 and -90 degrees from horizontal and will be held in place by a quick pin. A machine screw is drilled into the existing handle for use as a positioning stop in the slot on the handle design. The height difference between +90 and -90 can be adjusted to fit a variety of applications.

The second (slider design), Figure 6, allows for more positions in the vertical plane. The handle can be raised or lowered by unpinning the slider from the slot, selecting the desired height, and then repinning the slider.

Both of these design concepts should reduce the hazardous postures of the operator, but because they cause a deviation from the fixed handles common on swing grinders, the vibrational properties, control, and durability consideration will have to be analyzed to more fully develop the concepts. 
Another potential solution would be the use of scissors lifts to adjust the height of the work surface, rather than forcing employees to adjust themselves to the casting. These have been used with mixed results within the industry.

While these options help mitigate the ergonomic problem, the chance of musculoskeletal injuries still exist while human effort is still integral to the manipulation of the machine.



Figure 5: One of a pair of rotating adjustable handles for swing grinders

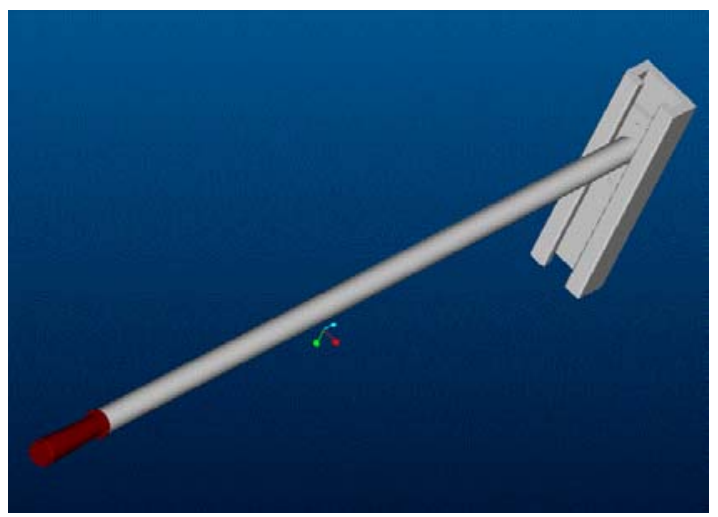

Figure 6: One of a pair of slider handles for swing grinders

\section{Jobs that did not pose significant ergonomic hazards}

Some of the chosen by the companies for review by the research team did not pose any significant ergonomic hazards. An example of this are burning and welding operations, in which the workstation allows the operator to assume a neutral position. This is much different than hand grinding, for instance, because the operator does not need to apply any force. Risks were also minimized by adequate provision and use of material handling equipment to move and position the castings. For such jobs, it is still advisable to allow the operator adequate breaks or 
job rotations to further minimize any problems associated with assuming postures for extended periods.

We discussed the poor positioning of the operator controls for chemically bonded molding lines above. Aside from this workstation design flaw, these operations seemed to be without any major ergonomic risk factors at some companies. This was the case, only when powered conveyors were utilized to move the flasks and molds on the conveyor line.

\section{Material handling that is not justified and should be eliminated}

With adequate equipment, material handling operations can usually be designed without much risk for the operators to develop musculoskeletal injuries. However, any elimination of excess handling is a sure way to eliminate all risks of such injures. It has been the experience of the authors, that there is much excess handling of castings in the steel casting industry. For instance, after grinding operations, castings are sometimes placed in a bin, to be moved to the heat treatment department, where they are again handled to be stacked on heat treatment racks. Elimination of some of these steps will result in productivity improvements, as well as reduction of ergonomic risks. Of course, proper design of the workstation at the areas in which material handling is deemed essential is still needed. However, elimination of some handling will allow a company to focus their improvement efforts at a smaller number of locations.

\section{Ergonomic hazards from material handling that are relatively easy to resolve}

One job that was relatively easy to resolve in many companies was shakeout. Shakeout lines were often not the correct height for workers to comfortably remove castings and storage bins were improperly placed to minimize material handling. An easy solution would be to equip a jib crane with an electro-magnet that is relatively easy to maneuver. If the use of an electro-magnet was not feasible, then the placement of slides from the shakeout line to designated storage bins will effectively minimize material handling. This will reduce the reach of the worker and allow them to stand next to the shakeout line to retrieve the castings. Figure 7 illustrates this suggestion. The previous design of the workstation presented in Figure 7 had the bins directly in front of the shakeout. This required the operator to use a six-foot hook, and fully extend his arms, to reach the castings. The switch to the solution proposed in Figure 7 will be very simple, and actually provides the operator with access to more bins than previously.

\section{Ergonomic hazards from material handling that are challenging to resolve}

Some companies have excessive material handling during the molding process. The majority of material handling results from manual moving of flasks, and the removal of the molds from the flask. Most of the companies visited had roller conveyors for the movement of these molds. The roller conveyors were sometimes not adequate for easy transport of the molds. In addition, the manual removal of molds from patterns is difficult and is a major risk for backs and shoulder injuries. One possible solution would be the installation of powered conveyors to ease the movement of the filled patterns/molds. Another solution includes the purchase of a rollover machine to eliminate the risk of injury when removing molds. 


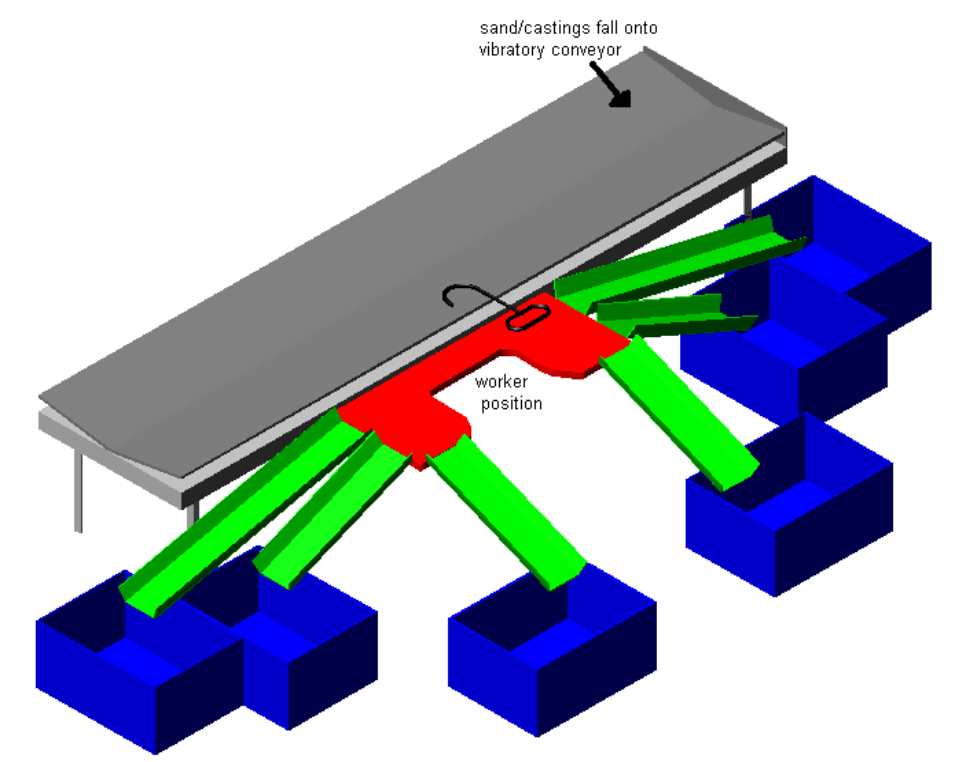

Figure 7: Shakeout line with guided slides to aid the operator while removing castings.

\section{A CLOSER LOOK AT HAND GRINDING}

Hand grinding was identified by most of the companies that we visited as a job that was causing ergonomic problems. The following discussion examines this particular job, and shows why it is challenging to solve from an ergonomic standpoint.

One of the major advantages of the metalcasting process is that it can produce complex shaped components. These complex shapes make it difficult to configure the grinder to allow cleaning operations. Essentially, there are three parts of the system that are able to conform. These are the operator, the grinder itself, or the casting. In the short term, the easiest part of the system to conform is the operator. The operators' ability to conform to a variety of postures, however, is often exploited. Figures 8-10 illustrate these three cases even further. Figure 8 shows the system with no flexibility in the orientation of the casting or grinding machine. The operator will be forced to conform, which often puts the body into ergonomically unsafe positions to complete the grinding operation. It is these types of positions, that the operators commonly must assume, that need to be eliminated or minimized. Figure 9 illustrates an adjustable handle, which can be used to help keep the worker in a safe, natural position more of the time. These drawings show a prototype that the team developed, but adjustable handles are also commercially available.

Figure 10 is a manipulator/positioner used to maneuver the casting. The manipulator is capable of rotating $360^{\circ}$ around the base stand and can position $90^{\circ}$ around the arm. With some custom fixturing the positioner will minimize how much the operator needs to conform. The positioner is not practical for large castings, but other solutions will be shown to at least partially mitigate the problem. 

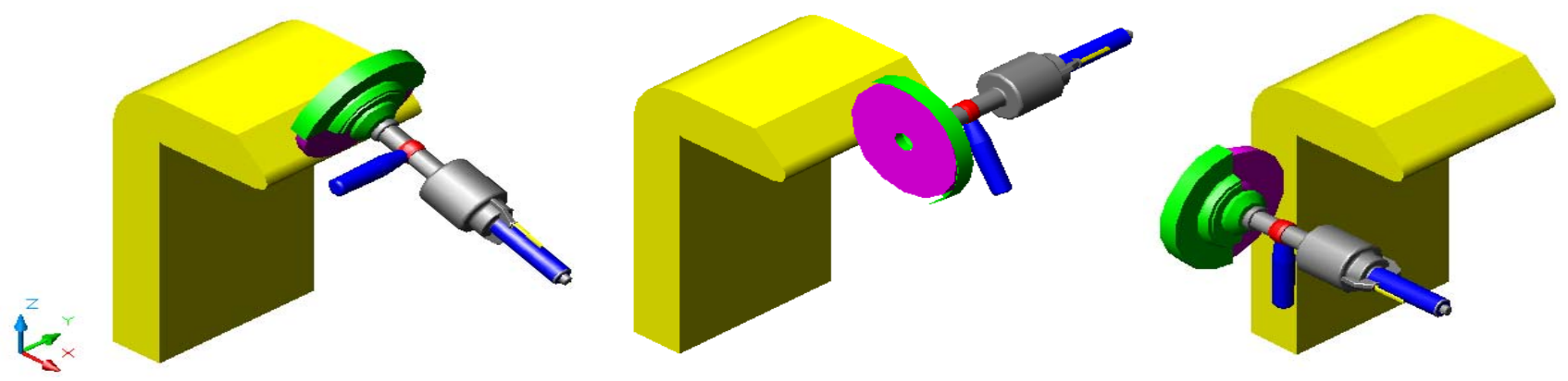

Figure 8: The operator is required to conform to grind on complex shaped castings.
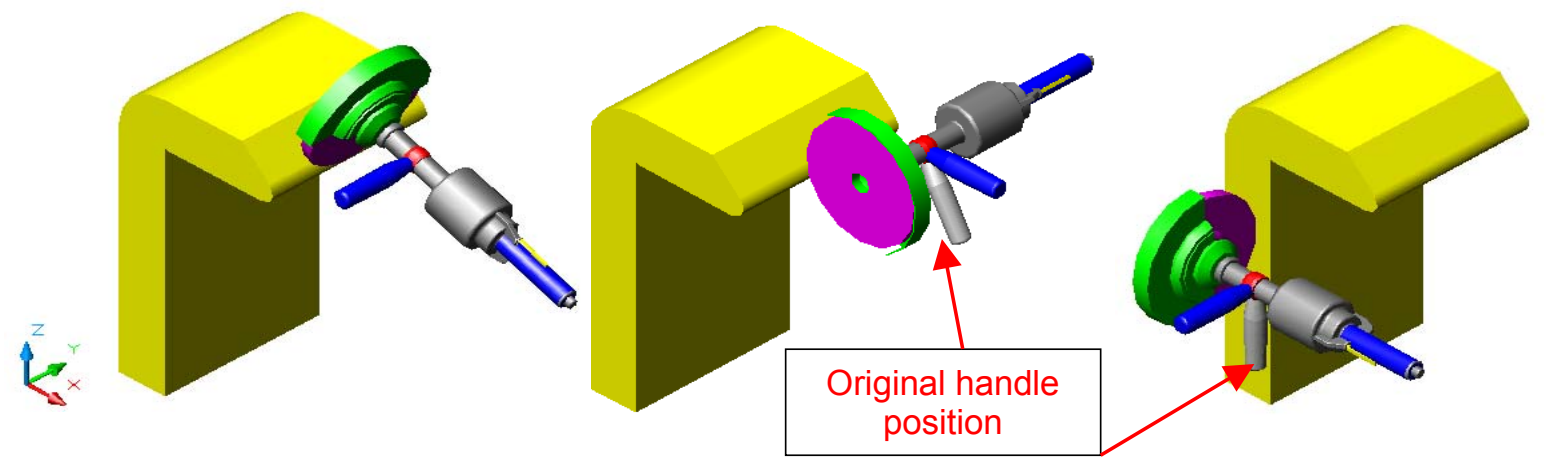

Figure 9: Adjustable handle for grinder to aid in keeping operator's hands in neutral position while grinding.
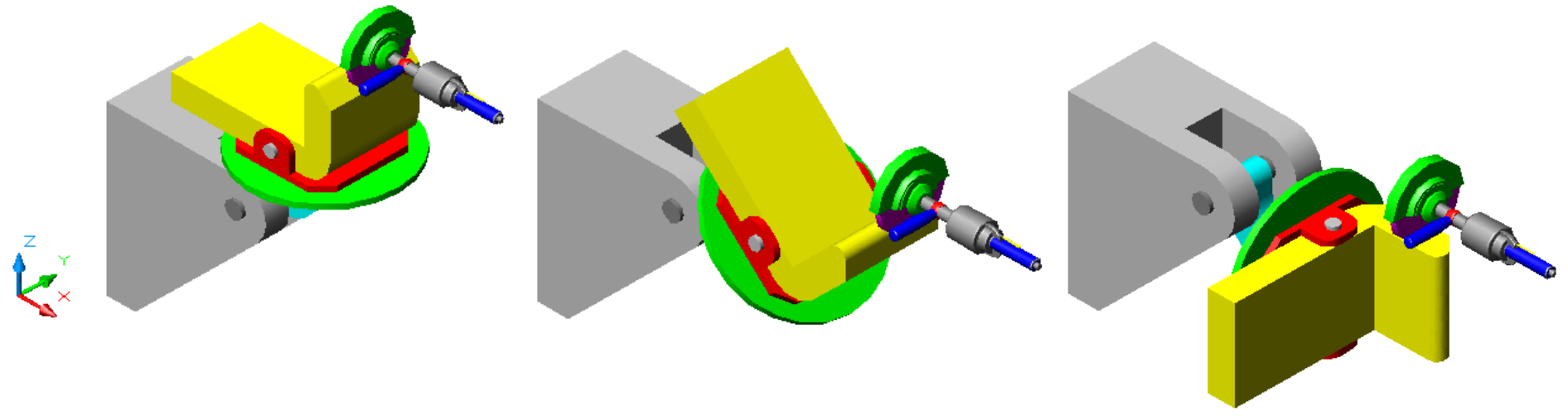

Figure 10: Manipulator, which will position casting to keep worker's hands and body in an ergonomically correct position 
Table 2 details some of the advantage and disadvantages of adapting the operator, as well as, the more ergonomically correct options of adapting the grinding machine or casting.

Table 2: Possible parts of the system that conform during hand grinding and the advantages and disadvantages of each.

\begin{tabular}{|c|c|c|c|}
\hline & Operator Conforming & $\begin{array}{l}\text { Grinding Machine } \\
\text { Conforming }\end{array}$ & Casting Conforming \\
\hline Description & 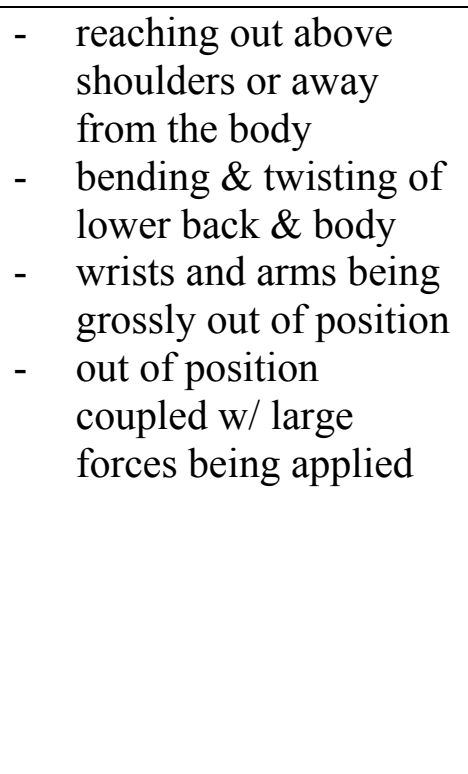 & 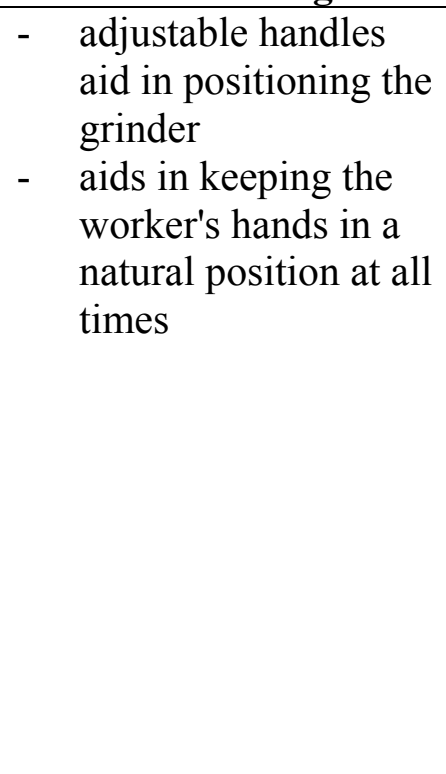 & 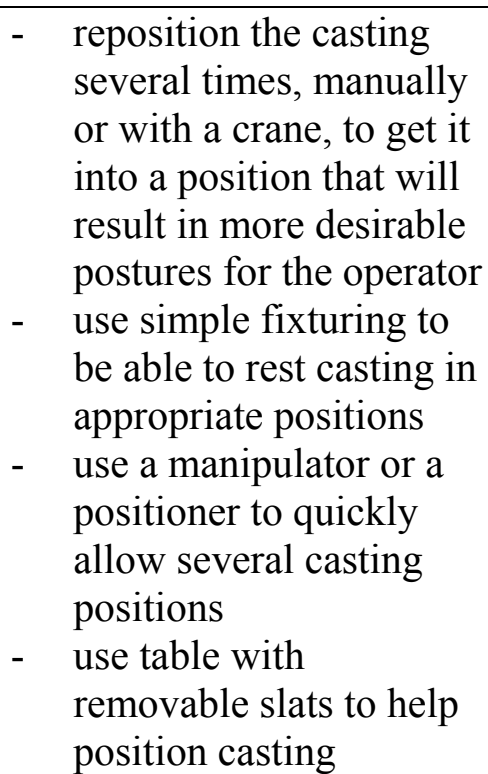 \\
\hline Advantages & - very flexible & $\begin{array}{ll}\text { - } & \text { quickly adjustable } \\
\text { - } & \text { ergonomically } \\
& \text { correct for hands \& } \\
& \text { elbows }\end{array}$ & $\begin{array}{l}\text { - ergonomically better for } \\
\text { human body }\end{array}$ \\
\hline Disadvantages & $\begin{array}{ll}\text { - } & \text { lower productivity } \\
\text { because of fatigue and } \\
\text { physical stress } \\
\text { - } & \text { very bad } \\
\text { ergonomically } \\
\text { - } & \text { leads to damage of } \\
\text { operators' hands, arms, } \\
\text { shoulders and lower } \\
\text { back }\end{array}$ & $\begin{array}{ll}\text { - } & \text { possibly hard to } \\
\text { apply force in some } \\
\text { configurations } \\
\text { - } \\
\text { more expensive than } \\
\text { straight handles }\end{array}$ & 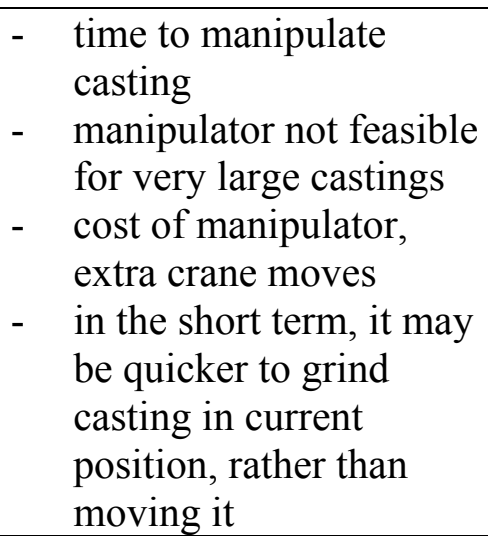 \\
\hline
\end{tabular}

These discussions were provided to help create a better understanding of the fundamentals of this problem. Table 3 provides the reader with a variety of options to minimize the ergonomic risk factors associated with hand grinding operations. We recommend that foundries strongly consider options 1, 2 and 3 of Table 3 . In addition, we feel that at least one of options 4, 5, 6, 7 or 8 be implemented to position the casting based on the size of the casting. These positioning options will not always allow the operator to assume more neutral positions. There will be times 
in which the operator will need to conform to the casting to complete the operation. These options will, however, provide some relief, which will minimize the risk of musculoskeletal injuries from developing or worsening.

Table 3: Solutions / recommendations matrix for hand grinding operations.

\begin{tabular}{|c|c|c|c|}
\hline Solution & Description & Reasoning & $\begin{array}{c}\text { Impact On } \\
\text { Productivity / Quality }\end{array}$ \\
\hline $\begin{array}{l}\text { Option } 1 \\
\text { Change } \\
\text { grinding } \\
\text { methods }\end{array}$ & $\begin{array}{l}\text { Replace hand grinding } \\
\text { with other methods, } \\
\text { such as swing grinding, } \\
\text { where feasible. } \\
\text { Consider swing } \\
\text { grinding with } \\
\text { horizontal and vertical } \\
\text { wheels. }\end{array}$ & $\begin{array}{l}\text { Swing grinding provides some } \\
\text { assistance with force application, } \\
\text { minimizing the ergonomic } \\
\text { hazards. }\end{array}$ & $\begin{array}{l}\text { Productivity should } \\
\text { increase. } \\
\text { Quality would be the same. }\end{array}$ \\
\hline $\begin{array}{l}\text { Option 2 } \\
\text { Eliminate } \\
\text { grinding }\end{array}$ & $\begin{array}{l}\text { Investigate and } \\
\text { eliminate excessive } \\
\text { grinding. }\end{array}$ & $\begin{array}{l}\text { Some companies are reporting } \\
\text { that castings are being over- } \\
\text { ground, and are exceeding } \\
\text { customer requirements. }\end{array}$ & $\begin{array}{l}\text { Productivity would } \\
\text { increase. } \\
\text { Quality would decrease, } \\
\text { but still above acceptable } \\
\text { levels. }\end{array}$ \\
\hline $\begin{array}{l}\text { Option 3 } \\
\text { Adjustable } \\
\text { Handle } \\
\text { Grinders }\end{array}$ & $\begin{array}{l}\text { Adjustable handle } \\
\text { grinders allow the } \\
\text { operators to quickly } \\
\text { adjust the position of } \\
\text { the grinder handles } \\
\text { (refer to Figure } 8 \text { ). } \\
\text { These grinders are } \\
\text { available from a } \\
\text { number of equipment } \\
\text { suppliers. }\end{array}$ & $\begin{array}{l}\text { The adjustable handles will } \\
\text { allow the workers to use the } \\
\text { grinder in various positions } \\
\text { while keeping their hands in the } \\
\text { neutral (comfortable, } \\
\text { ergonomically correct) position. } \\
\text { This, in turn, will reduce the risk } \\
\text { of wrist and arm injuries. }\end{array}$ & $\begin{array}{l}\text { With less fatigue, } \\
\text { productivity should } \\
\text { increase. } \\
\text { Small quality } \\
\text { improvements could be } \\
\text { expected. }\end{array}$ \\
\hline $\begin{array}{c}\text { Option } 4 \\
\text { Vices }\end{array}$ & $\begin{array}{l}\text { Bench vices are an } \\
\text { inexpensive option for } \\
\text { holding the casting in a } \\
\text { better position for the } \\
\text { operator. }\end{array}$ & $\begin{array}{l}\text { Vices will allow the worker to } \\
\text { apply forces to the casting in the } \\
\text { neutral (comfortable, } \\
\text { ergonomically correct) position } \\
\text { and reduce the risk of lower back } \\
\text { and shoulder injury. }\end{array}$ & $\begin{array}{l}\text { With less fatigue, } \\
\text { productivity should } \\
\text { increase. Vices should } \\
\text { have a small improvement } \\
\text { on quality of the castings. }\end{array}$ \\
\hline
\end{tabular}


Table 3 (continued): Solutions / recommendations matrix for hand grinding operations.

\begin{tabular}{|c|c|c|c|}
\hline $\begin{array}{l}\text { Casting } \\
\text { Positioner }\end{array}$ & $\begin{array}{l}\text { Casting positioners are } \\
\text { capable of rotating } \\
360^{\circ} \text { around the base } \\
\text { stand, can position } 90^{\circ} \\
\text { around the arm and be } \\
\text { adjustable in the } \\
\text { vertical direction. With } \\
\text { some custom fixturing } \\
\text { the positioner will } \\
\text { minimize how much } \\
\text { the operator needs to } \\
\text { conform (Figure } 10 \text { ). }\end{array}$ & $\begin{array}{l}\text { The positioner will allow the } \\
\text { worker to apply forces to the } \\
\text { casting in the neutral } \\
\text { (comfortable, ergonomically } \\
\text { correct) position and reduce the } \\
\text { risk of lower back and shoulder } \\
\text { injury. This will minimize the } \\
\text { problems shown in Figure } 8 \text {. }\end{array}$ & $\begin{array}{l}\text { The casting positioner } \\
\text { should have a small } \\
\text { improvement on both } \\
\text { productivity and product } \\
\text { quality. }\end{array}$ \\
\hline $\begin{array}{c}\text { Option 6 } \\
\text { Scissor Table }\end{array}$ & $\begin{array}{l}\text { The scissor table, } \\
\text { which can be an } \\
\text { inexpensive to } \\
\text { moderately expensive } \\
\text { option, can be used to } \\
\text { quickly position } \\
\text { castings to proper } \\
\text { working height. } \\
\text { Scissor tables are } \\
\text { available from a } \\
\text { number of equipment } \\
\text { suppliers. }\end{array}$ & $\begin{array}{l}\text { Scissor tables will allow } \\
\text { different sized workers to grind } \\
\text { on castings at a comfortable } \\
\text { height and in an ergonomically } \\
\text { correct position. This will } \\
\text { reduce the chance of operators } \\
\text { injuring their lower back. }\end{array}$ & $\begin{array}{l}\text { Scissor tables should have } \\
\text { an increase in productivity } \\
\text { and a small improvement } \\
\text { in the quality of the } \\
\text { castings. }\end{array}$ \\
\hline $\begin{array}{l}\text { Option } 7 \\
\text { Slat Table }\end{array}$ & $\begin{array}{l}\text { The slat table (Figure } \\
11 \text { ) is a relatively } \\
\text { inexpensive method for } \\
\text { positioning larger } \\
\text { castings. The slat table } \\
\text { can be built in-house } \\
\text { with little expense. }\end{array}$ & $\begin{array}{l}\text { The slat table will drastically } \\
\text { improve the worker's posture } \\
\text { and reduce the risk of lower back } \\
\text { injury to the workers. }\end{array}$ & $\begin{array}{l}\text { The slat tables should have } \\
\text { an increase in productivity } \\
\text { and a small improvement } \\
\text { in the quality of the } \\
\text { castings. }\end{array}$ \\
\hline $\begin{array}{l}\text { Option } 8 \\
\text { Large } \\
\text { Casting } \\
\text { Table }\end{array}$ & $\begin{array}{l}\text { For large castings, a } \\
\text { simple low sitting, } \\
\text { heavy frame or even } \\
\text { supporting blocks, will } \\
\text { get the workpiece at } \\
\text { better height for the } \\
\text { operator. This option } \\
\text { could also be built in- } \\
\text { house at a minimal } \\
\text { cost. }\end{array}$ & $\begin{array}{l}\text { By raising the casting from the } \\
\text { floor, the posture of the workers } \\
\text { would be improved. This } \\
\text { improvement in posture will } \\
\text { reduce the worker's risk of lower } \\
\text { back injury. }\end{array}$ & $\begin{array}{l}\text { An increase in } \\
\text { productivity, because of } \\
\text { less fatigue, and } \\
\text { improvement in quality of } \\
\text { the castings should result. }\end{array}$ \\
\hline
\end{tabular}



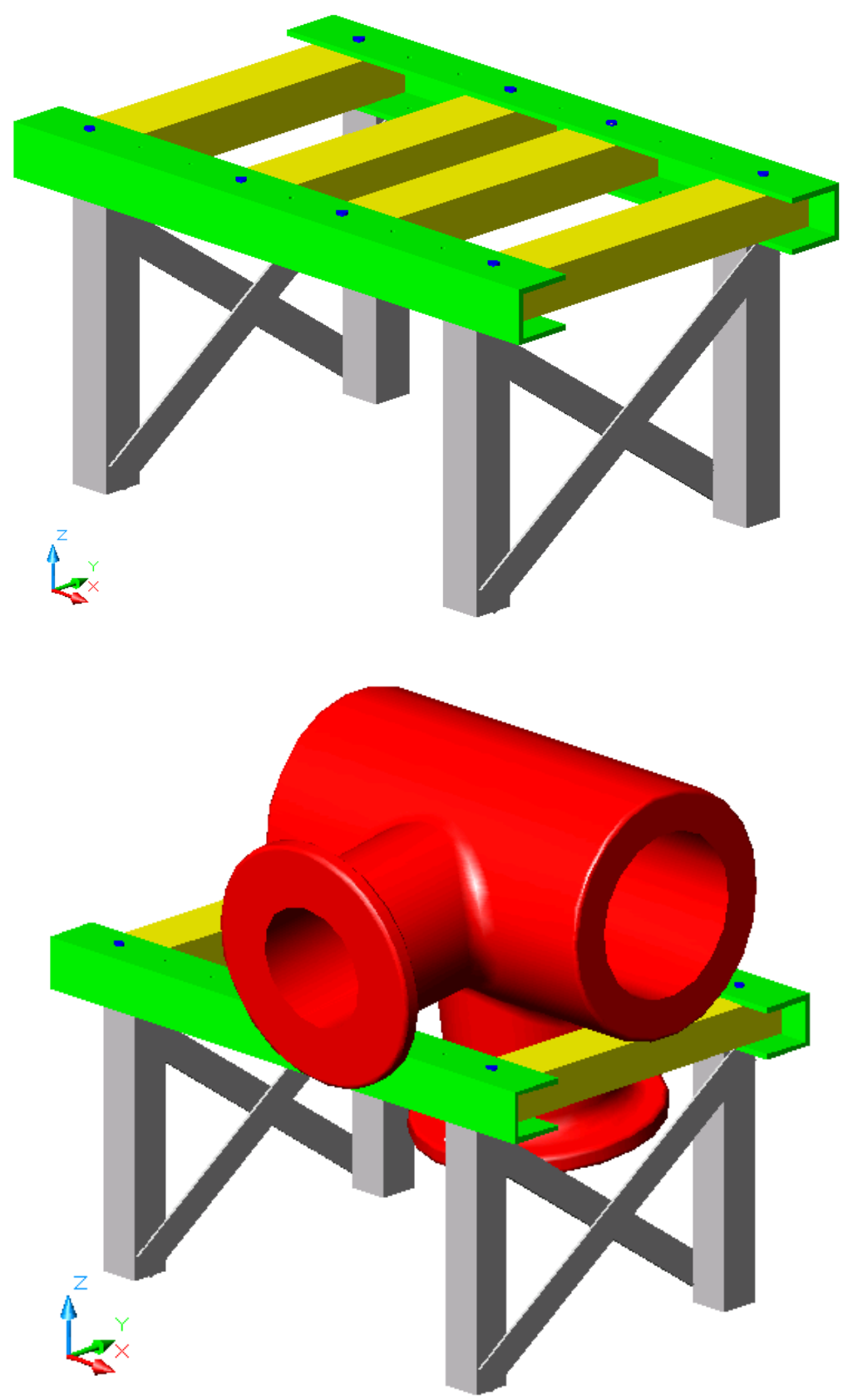

Color-Code Key for Adjustable Table.

\begin{tabular}{|c|c|c|c|c|c|}
\hline Part: & C-Channel & 4" x 6" Slats & $\begin{array}{c}\text { Placement } \\
\text { Bolts }\end{array}$ & Casting & $\begin{array}{c}\text { Legs \& Support } \\
\text { Braces }\end{array}$ \\
\hline Color: & & & & & \\
\hline
\end{tabular}

Figure 11: Table with adjustable/removable slats to position casting, and with slats placed to allow for a casting with obstructions. 


\section{PRESENTATIONS, TECHNOLOGY TRANSFER, AND WORK SESSIONS}

With the results of the survey as a guide, a workshop was developed. The major purpose of the workshop was to equip members of the industry with the tools they need to identify and begin to rectify ergonomic problems. To accomplish this, it was felt by the research team and the industrial steering committee that there was a need to make the workshop available to as many people as possible. As more people are aware of the issues, there is a higher probability and faster implementation of improvements. The workshop was offered four times in summer 2000, in different regions of the country, and attended by 43 industrial personnel. The participants were provided with the workshop materials, a variety of checklists to assist them in making ergonomic assessments at their facilities. The workshop worked through some examples to solve these problems.

A website was created and made available to the industry with much of the material presented at the workshop, such as check sheets and other evaluation tools.

Several presentations were made to the metalcasting industry. These events included a presentation at a regional steel casting event in Milwaukee, two presentations to a national casting event in Chicago, two poster sessions in Chicago, and a presentation to a national event in Kansas City. Two papers were also published. Presentations to industry research steering committee were also made.

Two ergonomic work sessions were held to more effectively transfer the knowledge gained to the targeted audience. These were held in March and October of 2001. During these events, ergonomic solutions were reviewed, discussed, and debated. For each of the job categories discussed, some selected videotape segments were presented and the problems were identified. The videotapes were chosen from several companies to highlight the issues. The research team presented their ideas to remedy the problems identified. The attendees were broken into groups to discuss the ideas presented, their experience related to the job, and as a group developed what they felt was ultimately the best solution. These findings were presented to the entire group, and further discussion was held.

By their nature, one of the most effective technology transfer activities, however, was the ergonomic assessment visits. The research team was able to interface with the employees and management to promote the need for better ergonomics. This was followed up with a written report of the findings and improvements that were produced for each of the 26 industrial sites visited.

\section{CONCLUSIONS}

Ergonomic problems are a major issue facing the steel foundry industry. The development of appropriate solutions requires a thorough understanding of ergonomic principles and work practices. Many problem solutions can be conceptualized through the combined efforts of knowledgeable management and the operators. These solutions can then be designed, developed, and fabricated in house, resulting in huge savings in procurement costs. The benefits of using an ergonomics enhanced approach to production system improvements will result in not 
only cost savings, but also increased worker productivity and motivation. Many of the solutions, which apply to more than a specific company, were discussed here. Results of a survey of the steel casting industry on ergonomics were also presented.

\section{REFERENCES}

Armstrong, T. J. (1986). Ergonomics and cumulative trauma disorders. Hand Clinics 2(3):553565.

Erdil, M., O. B. Dickerson, and E. Glackin (1994). Cumulative trauma disorders of the upper extremity. In Occupational Medicine, 3rd ed. C. Zenz, O. B. Dickerson, and E. P. Horvath (eds.), Mosby, St. Louis.

Garg, A., and J. S. Moore (1992). Prevention strategies and the low back in industry. Occupational Medicine: State of the Art Reviews 7(4): 629-640.

Hoozemans, M.J.M., van der Beek, A.J., Frings-Dresent, M.H.W., van Duk, F.J.H., van der Woude, L.H.V. (1998). Pushing and pulling in relation to musculoskeletal disorders: a review of risk factors. Ergonomics. 41(6): 757-781.

Leamon, T. (1994) Research to reality: A critical review of the validity of various criteria for the prevention of occupationally induced low back pain disability. Ergonomics. 37(12): 1959-1974.

Marras, W., Lavender, S., et al. (1995) Biomechanical risk factors for occupationally related low back disorders. Ergonomics. 38(2): 377-410.

Peters, F., M. Beyersdorfer, and T. VanVoorhis, "Instigating Changes to Production Systems," Steel Founders' Society of America-Technical and Operating Conference, Chicago, Illinois, November 2000.

Peters, F., T. VanVoorhis, and T. Rolling, "Re-Engineering Casting Production Systems Successes and Opportunities," Steel Founders' Society of America Technical and Operating Conference, Chicago, Illinois, November 1999.

Pope, M. (1989) Risk indicators in low back pain. Annals of Medicine. 21(5): 387.

Silverstein, B., Fine, L., Armstrong, T. (1987) Occupational factors and carpal tunnel syndrome. Am. Journal of Industrial Medicine. 11: 343-358

Silverstein, B., Fine, L., Armstrong, T. (1986) Hand wrist cumulative trauma disorders in industry. British Journal of Industrial Medicine. 43: 779-784.

USDOL, Bureau of Labor Statistics. (1990) Record keeping guidelines for occupational injuries and illness in the United States by Industry, 1977-1988. Wash. D.C. Govt. Printing Office.

Vikari-Juntura, E.R.A. (1997) The scientific basis for making guidelines and standards to prevent work-related musculoskeletal disorders. Ergonomics. 40(10): 1097-1117. 